Published in final edited form as:

Chem Res Toxicol. 2016 May 16; 29(5): 892-900. doi:10.1021/acs.chemrestox.6b00054.

\title{
Inhibitors of 7-Dehydrocholesterol Reductase: Screening of a Collection of Pharmacologically Active Compounds in Neuro2a Cells
}

\author{
Hye-Young H. Kim ${ }^{\dagger, \perp}$, Zeljka Korade ${ }^{\ddagger, \S, \perp}$, Keri A. Tallman ${ }^{\dagger}$, Wei Liu ${ }^{\dagger}$, C. David Weaver", \\ Karoly Mirnics $\$, \S$, and Ned A. Porter ${ }^{*}, \dagger, \ddagger$ \\ †Department of Chemistry and Vanderbilt Institute of Chemical Biology, Vanderbilt University, \\ Nashville, Tennessee 37235, United States \\ ¥Vanderbilt Kennedy Center for Research on Human Development, Vanderbilt University, \\ Nashville, Tennessee 37235, United States \\ §Department of Psychiatry, Vanderbilt University, Nashville, Tennessee 37235, United States \\ "Department of Pharmacology and Vanderbilt Institute of Chemical Biology, Vanderbilt University, \\ Nashville, Tennessee 37235, United States
}

\section{Abstract}

\begin{abstract}
A small library of pharmacologically active compounds (the NIH Clinical Collection) was assayed in Neuro2a cells to determine their effect on the last step in the biosynthesis of cholesterol, the transformation of 7-dehydrocholesterol (7-DHC) to cholesterol promoted by 7-dehydrocholesterol reductase, DHCR7. Of some 727 compounds in the NIH Clinical Collection, over 30 compounds significantly increased 7-DHC in Neuro2a cells when assayed at $1 \mu \mathrm{M}$. Active compounds that increased 7-DHC with a $Z$-score of +3 or greater generally gave rise to modest decreases in desmosterol and increases in lanosterol levels. Among the most active compounds identified in the library were the antipsychotic, antidepressant, and anxiolytic compounds that included perospirone, nefazodone, haloperidol, aripiprazole, trazodone, and buspirone. Fluoxetine and risperidone were also active at $1 \mu \mathrm{M}$, and another 10 compounds in this class of pharmaceuticals were identified in the screen at concentrations of $10 \mu \mathrm{M}$. Increased levels of 7-DHC are associated with Smith-Lemli-Opitz syndrome (SLOS), a human condition that results from a mutation in the gene that encodes DHCR7. The SLOS phenotype includes neurological deficits and congenital malformations, and it is linked to a higher incidence of autism spectrum disorder. The significance of the current study is that it identifies common pharmacological compounds that may induce a biochemical presentation similar to SLOS. Little is known about the side effects of elevated 7-
\end{abstract}

\footnotetext{
"Corresponding Author: Phone: 615-343-2693. Fax: 615-343-5478. n.porter@ vanderbilt.edu.

${ }$ H.-Y.H.K. and Z.K. contributed equally to this publication.

Supporting Information

The Supporting Information is available free of charge on the ACS Publications website at DOI: 10.1021/acs.chemrestox.6b00054. Structures of compounds that are active at 1 and $10 \mu \mathrm{M}$ in Neuro2a cells and a list of compounds that are active at $1 \mu \mathrm{M}$ in Dhcr7deficient Neuro2a cells (PDF)

Notes

The authors declare no competing financial interest.
} 
DHC postdevelopmentally, and the elevated 7-DHC that results from exposure to these compounds may also be a confounder in the diagnosis of SLOS.

\section{Graphical abstract}

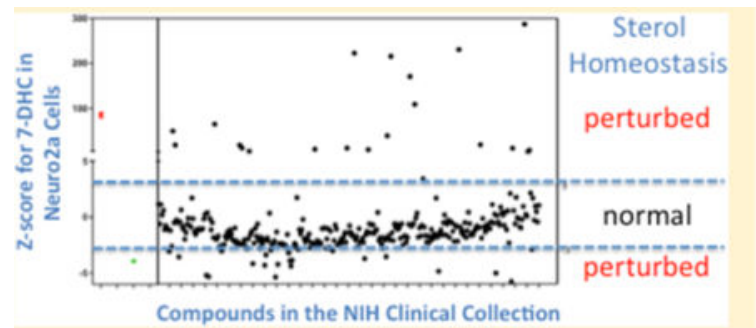

\section{INTRODUCTION}

The inhibition of cholesterol biosynthesis has been of longstanding interest. ${ }^{1}$ The development of statins, the biggest selling pharmaceuticals of all time, is one of the triumphs of the modern pharmaceutical industry. ${ }^{2}$ These compounds inhibit the transformation of acetate into mevalonate, controlling the entire biosynthesis pathway, as shown in Figure 1. The inhibition of subsequent steps in the cholesterol biosynthesis pathway has also been explored as a strategy for controlling cholesterol levels, but this approach has generally failed. Many compounds that inhibit late-stage sterol transformations promoted by 7 dehydrocholesterol reductase (DHCR7), for example, have failed as drugs because of the teratogenicity of these compounds. ${ }^{3}$ AY9944 [trans-1,4-bis(2-chloro-benzylaminomethyl) is one example of a small molecule teratogen that inhibits the conversion of 7dehydrocholesterol (7-DHC) to cholesterol and 7-dehydrodesmosterol (DHD) to desmosterol (Des) as shown in Figure 1. Cholesterol levels are significantly reduced, and 7DHC levels are increased in animals exposed to AY9944. Exposure of pregnant animals to this compound results in miscarriage, preterm births, and severe physical deformities of any offspring that survive. ${ }^{3}$

These AY9944-treated rats serve as a rodent pharmacological model for Smith-Lemli-Opitz syndrome (SLOS) ${ }^{4-9}$ a human condition that results from mutations in the gene that encodes DHCR7. ${ }^{10-17}$ This recessive disorder is biochemically characterized by both higher levels of 7-DHC and lower levels of cholesterol than is considered normal in all tissues. The range of severity in SLOS is wide, and it depends on the DHCR7 mutation inherited, over 150 of which have been reported. ${ }^{18,19}$ The consequence of the genetic defect is a broad spectrum of phenotypes that include congenital malformations and neurological deficits, with more than $50 \%$ of SLOS cases receiving the diagnosis of autism spectrum disorder. ${ }^{20,21}$ There is an unusually high carrier frequency for this recessive disorder. Recent studies estimate that about $1 \%$ of the population carry one copy of a mutant DHCR7gene (1 in 30 to 1 in 100). ${ }^{17,22}$

While small molecule inhibitors of DHCR7 have been the object of extensive pharmacological investigation and have been used to create rodent models for SLOS, ${ }^{4-7}$ it has only been in recent years that a measurable link between prescribed pharmaceuticals in a 
population and the perturbation of sterol homeostasis has been reported. In a recent study, ${ }^{23}$ medical records of patients with elevated plasma 7-DHC, but a false-positive SLOS diagnosis, were linked to prescribed aripiprazole, an atypical antipsychotic or trazodone, an antidepressant. The authors of this study note that both aripiprazole and trazodone are listed as Category $\mathrm{C}$ drugs during pregnancy, ${ }^{23}$ which means that reproduction studies have shown an adverse effect on the fetus but that potential benefits may warrant use of the drug in pregnant women despite potential risks.

Given the links between 7-DHC, the effect of small molecules on DHCR7, and the devastating human disorder SLOS, it seems important to know whether other prescribed pharmaceuticals affect this important biochemical transformation. This question stimulated us to initiate a search for small molecules of clinical importance that affect cholesterol biosynthesis at the DHCR7 step. We report here the results of a screen of some 730 compounds in the NIH Clinical Collection, $5 \%$ of which at $1 \mu \mathrm{M}$ give rise to a significant increase of 7-DHC in Neuro2a cells.

\section{MATERIALS AND METHODS}

\section{Materials}

Unless otherwise noted, all chemicals were purchased from Sigma-Aldrich Co (St. Louis, MO). HPLC grade solvents were purchased from Thermo Fisher Scientific Inc. (Waltham, MA). All cell culture reagents were from Mediatech (Manassas, VA), Life Technologies (Grand Island, NY), and Greiner Bio-One GmBH (Monroe, NC). Standard $d_{7}$-Chol was purchased from Medical Isotopes, Inc., and $d_{7}$-7-DHC, ${ }^{13} \mathrm{C}_{3}$-Lan, and ${ }^{13} \mathrm{C}_{3}$-Des were synthesized as previously described. ${ }^{24,25}$

\section{Cell Cultures and the Screening Method: Neuro2a}

The neuroblastoma cell line Neuro2a was purchased from American Type Culture Collection (Rockville, MD). Neuro2a were maintained in DMEM supplemented with Lglutamine, $10 \%$ fetal bovine serum (FBS; Thermo Scientific HyClone, Logan, UT), and penicillin/streptomycin at $37{ }^{\circ} \mathrm{C}$ and $5 \% \mathrm{CO}_{2}$. Chemicals were deposited in a 384 cell culture plate (Greiner Bio-One) using a Labcyte Echo 550/555 (Sunnyvale, CA) liquid handler equipped in the Vanderbilt University High-throughput Screening Facility. Neuro2a cells were trypsinized, counted, resuspended in DMEM medium with reduced serum $(0.5 \%$ FBS), and dispensed to 384-well plates (on top of predeposited compounds) using Multidrop Combi (ThermoScientific). Plating density was $5 \times 10^{4} / \mathrm{cm}^{2}$. After $24 \mathrm{~h}$ of incubation at $37{ }^{\circ} \mathrm{C}$ and $5 \% \mathrm{CO}_{2}$, Hoechst dye (Molecular Probes) was added using Multidrop Combi and incubated at room temperature for $30 \mathrm{~min}$ in the dark. Cells were imaged using ImageXpress Micro XL (Molecular Devices, Sunnyvale, CA) with a 10× objective. Following imaging, the medium was removed, and $80 \mu \mathrm{L}$ of $\mathrm{MeOH}$ containing internal standards $(0.0165 \mathrm{nmol}$ for $d_{7}$-7-DHC, $0.125 \mathrm{nmol}$ for ${ }^{13} \mathrm{C}_{3}$-Des, and $0.115 \mathrm{nmol}$ for ${ }^{13} \mathrm{C}_{3}$-Lan/well) was added using the Multidrop Combi. The 384-well plate was placed on a rotary shaker for $20 \mathrm{~min}$ at room temperature and then centrifuged for $10 \mathrm{~min}$ using a Sorvall swing rotor. The supernatant was transferred by an automated liquid handler Agilent Velocity 11 Bravo to a 4-phenyl-1,2,4-triazoline-3,5-dione (PTAD)-predeposited plate (Waters \#186002631, $100 \mu \mathrm{L}$ 
flat bottomed). The method of analysis is based on a derivatization of 7-DHC in a DielsAlder reaction with PTAD, and the details of the derivatization procedure have been previously described. ${ }^{25,26}$ The plates were immediately sealed with Easy Pierce Heat Sealing Foil (ThermoScientific AB-1720), followed by 20 min of agitation at room temperature. The sealed plates were kept in $-80{ }^{\circ} \mathrm{C}$ until LC-MS analysis.

\section{LC-MS (SRM) Analysis}

The sealed plates were placed in an Acquity UPLC system equipped with ANSI-compliant well plate holder. Ten microliters was injected onto the column (Acquity UPLC BEH C18, $1.7 \mu \mathrm{m}, 2.1 \times 50 \mathrm{~mm})$ with $100 \% \mathrm{MeOH}(0.1 \%$ acetic acid) mobile phase for 1 min runtime at a flow rate of $300 \mu \mathrm{L} / \mathrm{min}$. The monitored transitions included 7-DHC $560 \rightarrow 365, d_{7}-7$ DHC $567 \rightarrow 372$, desmosterol $592 \rightarrow 365,{ }^{13} \mathrm{C}_{3}$-desmosterol $595 \rightarrow 368$, lanosterol $634 \rightarrow$ 602 , and ${ }^{13} \mathrm{C}_{3}$-lanosterol $637 \rightarrow 605$ with retention times of $0.8,0.5$, and $0.6 \mathrm{~min}$, respectively.

\section{Lipid Extraction, Separation, and GC-MS Analyses of Sterols in Cells}

Verification of the hits obtained from the initial screening was carried out with varying concentrations of the compounds of interest. In addition, a more complete sterol profile was determined. The experiment was carried out in 96 well plates as described above for the 384 well plates. After counting cells on ImageXpress Micro XL (10X objective), the medium was removed, the cells were washed with PBS, and the buffer was removed. The plates were stored at $-80{ }^{\circ} \mathrm{C}$. To each well was added $10 \mu \mathrm{L}$ of BHT/TPP solution $(2.5 \mathrm{mg}$ of TPP and 1 $\mathrm{mg}$ of BHT in $1 \mathrm{~mL}$ of EtOH), $10 \mu \mathrm{L}$ of internal standard solution $\left(0.87 \mathrm{nmol}\right.$ for $d_{7}$-Chol, $0.033 \mathrm{nmol}$ for $d_{7}$-7-DHC, $0.25 \mathrm{nmol}$ for ${ }^{13} \mathrm{C}_{3}$-Des, and $0.23 \mathrm{nmol}$ for ${ }^{13} \mathrm{C}_{3}$-Lan/well), and $200 \mu \mathrm{L}$ of $\mathrm{MeOH}$. The plate was placed on a rotary shaker for $20 \mathrm{~min}$ at room temperature. An aliquot $(100 \mu \mathrm{L})$ of the supernatant was transferred to a PTAD-predeposited plate, sealed with Easy Pierce Heat Sealing Foil, followed by 20 min of shaking at room temperature, and analyzed by LC-MS as described above. The flow rate was increased to $500 \mu \mathrm{L} / \mathrm{min}$ and run time to $1.5 \mathrm{~min}$ to include cholesterol analysis (Chol $369 \rightarrow 369$ and $d_{7}$-Chol $376 \rightarrow 376$ ). The remaining sample in each well was transferred to vials and concentrated on a SpeedVac concentrator for GC-MS analysis. To each vial was added $\mathrm{N}, \mathrm{O}$-bis(trimethylsilyl)trifluoroacetamide (BSTFA, $50 \mu \mathrm{L}$ ), vortexed well, and allowed to react for $30 \mathrm{~min}$. The sample ( $5 \mu \mathrm{L}$ ) was injected onto the column (SPB-5, $0.25 \mu \mathrm{m}, 0.32 \mathrm{~mm} \times 30 \mathrm{~m}$ ) with a temperature program of $220-300^{\circ}(5 \mathrm{~min})$ at $20^{\circ} / \mathrm{min}$ and helium flow rate of $2.0 \mathrm{~mL} / \mathrm{min}$. The data were collected in full scan mode and the following ions extracted for quantitation relative to $d_{7}$-Chol: 458 for cholesterol, zymostenol, lathosterol; 456 for zymosterol, dehydrolathosterol; 349 (M-105) for dehydrodesmosterol; 393 (M-105) for lanosterol; 395 (M-105) for dihydrolanosterol; 486 for dimethylzymostenol; and 465 for $d_{7}$-cholesterol. Desmosterol and 7-DHC were not analyzed by GC-MS because they coelute. The remaining sterol intermediates were not detected. All data were normalized to cell count.

\section{Statistical Analysis}

All calculations of variability, standard deviation (SD), and normalized SD were performed in Microsoft Excel or GraphPad Prism. In addition, we calculated screening window 
coefficients, " $Z$ " and ' $Z$ '-Score". ${ }^{27}$ These factors reflect the assay dynamic range and data variation associated with the measurements.

\section{RESULTS}

Recent advances in methods for sterol analysis now permit the screening of modest-sized libraries of pharmaceutical agents to identify compounds that alter cellular levels of 7-DHC and other cholesterol precursors. These methods rely on a sterol derivatization with the dienophile 4-phenyl-1,2,4-triazoline-3,5-dione (PTAD) and a UPLC-MS protocol that permits the assay of several sterols in a run-time of less than a minute..$^{25,26}$ Deuterium and ${ }^{13} \mathrm{C}$ labeled sterols, synthesized in our laboratories, facilitate the analysis of sterols in cell culture by standard isotope dilution methods. Our analytical protocol thus includes the addition of known amounts of isotopically labeled $d_{7}$-cholesterol, $d_{7}$-7-DHC, and ${ }^{13} \mathrm{C}_{3^{-}}$ desmosterol to a lysate of cells in culture that have been previously exposed to a pharmaceutical agent for $24 \mathrm{~h}$. Determination of 7-DHC and desmosterol levels by UPLCMS analysis with simultaneous selected reaction monitoring (SRM) for endogenous sterols and exogenous isotopically labeled standards along with HTS cell counting of a 384-well plate provides a readout of compound activity on cholesterol biosynthesis at the 7-DHC $\rightarrow$ cholesterol or desmosterol $\rightarrow$ cholesterol steps. Lanosterol was also determined in our analysis by comparison of endogenous lanosterol levels with added ${ }^{13} \mathrm{C}_{3}$-lanosterol. Picomolar levels of 7-DHC, desmosterol, and lanosterol could be measured, among other sterols, making analysis of a few thousand cells or $20 \mu \mathrm{L}$ of human plasma relatively straightforward. Neuro2a cells, a mouse neuroblastoma cell line frequently used in the neuroscience community to model neuronal cells, were used in this study. The cells double in about $24 \mathrm{~h}$, and they can be readily adapted for use in a 96- or 384-well format.

The $~ 730$ compounds in the NIH Clinical Collection were distributed on three 384-well plates. Each plate also had 24 control wells with DMSO only, and there were 10 wells each for reference compounds that included aripiprazole $(100 \mathrm{nM})$ and pitavastatin $(100 \mathrm{nM})$. Duplicates of the three plates were prepared, and the six plates were analyzed by the UPLCMS method. The reliability of the screen on each plate was assessed by the determination of $Z$ values by comparison of 7-DHC levels measured in the multiple control and aripiprazole wells. ${ }^{28}$ Figure 2 shows the 7-DHC levels in the DMSO control and $100 \mathrm{nM}$ aripiprazole wells for the six plates along with the calculated $z$ s, all of which fall in the $0.2-0.6$ range generally considered acceptable for an HTS screen but which suggest rescreening of hits for validation. ${ }^{28}$ In order to maximize the number of hits of potentially active compounds, we chose a library concentration of $1 \mu \mathrm{M}$ for our standard 384-well screens, an order of magnitude higher than the "aripiprazole standard" used to determine $z \mathrm{~s}$ but a concentration that is still pharmacologically relevant.

Figure 3 presents the results of a 384-well plate screen at $1 \mu \mathrm{M}$ of 320 of the compounds in the NIH Clinical Collection. Neuro2a cells were treated with compounds for $24 \mathrm{~h}$ and then counted automatically, sterols were determined by UPLC-MS, and the cellular level of 7DHC in nanomol/million cells was then converted to a Z-score ${ }^{28}$ so that multiple plates could be compared. 
Aripiprazole was found to reproducibly increase levels of 7-DHC and reduce levels of desmosterol in each plate analyzed, while pitavastatin reduced levels of all sterols analyzed; see Figure 3 in which aripiprazole data are shown in red and pitavastatin in green. These observations are consistent with these drugs acting on DHCR7 and HMGCR, respectively, in the cholesterol biosynthetic pathway. Analysis of the data for the duplicate screen of the entire NIH Clinical Collection indicated that some 34 compounds in the library were found to increase 7-DHC levels above a threshold Z-score of +3 . One of the compounds identified as being active in the initial 384-well screen (Captopril) was not validated in the triplicate rescreen of these hits. Several of the 34 compounds identified in the screen were antipsychotic, antidepressant, or anxiolytic medications, an observation that led us to separately screen all compounds in the collection that have antipsychotic, antidepressant, or anxiolytic properties. This screening was done in triplicate at 1 and $10 \mu \mathrm{M}$ on 96 -well plates, and three additional compounds were identified that had a significant effect on 7-DHC levels at $1 \mu \mathrm{M}$ in Neuro2a cells.

The 37 compounds that gave significant increases in 7-DHC in Neuro2a cells at $1 \mu \mathrm{M}(\mathrm{Z}-$ score $>+3$ ) are presented in Figure 4 in the order of decreasing 7-DHC levels found in the assay, and the structures of these compounds are presented in Supporting Information (Table S1). Figure 4 also presents compounds in the Collection that affect levels of desmosterol (Figure 4B) and lanosterol (Figure 4C) in Neuro2a cells. Background desmosterol levels in Neuro2a cells are high, and the increase in desmosterol caused by small molecules in the library is attenuated compared with the increases observed for 7-DHC and lanosterol, both of which have very low background levels. This is shown in Figure 4 in which the maximum desmosterol Z-score difference for treated and untreated Neuro2a cells is less than +10 (Figure 4B), while Z-scores for 7-DHC and lanosterol (Figures 4A and C) are as high as +300 .

Most of the compounds that significantly increase 7-DHC levels in Neuro2a cells (shown in Figure 4A) also show a modestly elevated level of lanosterol as well as a reduced level of desmosterol after treatment. This is shown in Figure 5 for triplicate experiments in which Neuro2a cells were assayed for sterols after exposure to $1 \mu \mathrm{M}$ of drug for $24 \mathrm{~h}$. Five of the six compounds shown in the Figure, perospirone, aripiprazole, trazodone, ifenprodil, and risperidone give results typical of most of the hit compounds shown in Figure 4A. In contrast to most of the compounds, $1 \mu \mathrm{M}$ nefazodone gives rise to a sterol profile in which desmosterol is also elevated as a result of the incubation. Of the active compounds identified in the 384-well screen shown in Figure 4A, only nefazodone, dofetilide, and fluoxetine give rise to elevated levels of both 7-DHC and desmosterol, all other compounds show a small decrease in desmosterol levels. Cholesterol in Neuro2a cells is only marginally affected as a result of a $1 \mu \mathrm{M}$ exposure to any of the hit compounds shown in Figure 4A during the course of a $24 \mathrm{~h}$ incubation.

When exposure concentrations of antidepressant/antipsychotic medications in Neuro2a are increased to $10 \mu \mathrm{M}$, elevated 7-DHC with a Z-score greater than 3 is found for treatments with 10 additional drugs. In the order of decreasing activity, the compounds found to be active at $10 \mu \mathrm{M}$ are bupropion, sertraline, nortriptyline, clomipramine, maprotiline, amitriptyline, desipramine, amoxapine, imipramine, and mosapride, and their structures are 
presented in Table S2. It should be noted that there is associated toxicity with incubations at $10 \mu \mathrm{M}$ concentrations for most of these compounds, as seen by a decrease in cell numbers for the treated cells compared to the controls after $24 \mathrm{~h}$. This is in contrast to the experiments at $1 \mu \mathrm{M}$ where toxicity was not an issue for the active compounds, and cell numbers were unaffected by any of the compounds screened at this concentration. Fluoxetine (prozac) and sertraline (zoloft) show significant toxicity at $10 \mu \mathrm{M}$ with particularly low cell numbers found in Neuro2a after $24 \mathrm{~h}$.

At the same time that the NIH Clinical Collection was screened in Neuro2a cells, a duplicate screen of the same library was carried out with Dhcr7-deficient Neuro2a cells that have been used as a cellular model for SLOS. 7-DHC levels in these Dhcr7-deficient cells are significantly higher than that in control Neuro2a, and they have previously proven useful in screens to identify small molecules that decrease levels of 7 -DHC in cell culture. ${ }^{25}$ Small molecules that interrupt the biosynthesis at the lanosterol or zymosterol intermediate stages, for example (see Figure 1), suppress levels of 7-DHC and can be identified from the Dhcr7deficient cells in culture.

Screens of the NIH Clinical Collection with Dhcr7-deficient cells identified several compounds in the library that caused a significant increase of 7-DHC in this cell line. Table 1 presents a list of drugs that increase levels of 7-DHC only in control Neuro2a and in both control and Dhcr7-deficient Neuro2a cells. Thirteen compounds were active in both cell lines with $\mathrm{Z}$ scores greater than +3 (99.9\% confidence) for both, while 24 compounds caused a significant increase of 7-DHC only in Neuro2a cells. Ten compounds increased 7DHC in Dhcr7-deficient Neuro2a cells alone (see Table S3), but Z-scores were only modest, and the compounds showed little activity in control Neuro2a cells.

\section{DISCUSSION}

\section{SLOS and SLOS Pharmacological Rodent Models}

7-Dehydrocholesterol accumulates in tissues and fluids of patients with Smith-Lemli-Opitz syndrome, a recessive neurodevelopmental disorder caused by mutations in the gene encoding 3-hydroxysterol-reductase (DHCR7; EC 1.3.1.21). Although the exact mechanism of the syndrome is not understood, cholesterol deficiency and/or the buildup of 7-DHC is generally thought to be critical to the pathobiology of SLOS. An animal model of SLOS $4-8$ has been developed by treating pregnant rats with AY9944, a selective inhibitor of DHCR7, the same enzyme that is affected in SLOS. Levels of 7-DHC are elevated, and cholesterol is reduced in tissues and fluids of the AY9944 rat pups, and the same biochemical hallmarks that are found in the Dhcr7-null mouse. 7-DHC derived oxysterols have also been isolated from the brain, liver, and serum from the Dhcr7-null mouse and the AY9944 rat, both of which have been used extensively to study the phenotype and pathogenesis of SLOS. ${ }^{29}$

We reason that any pharmacological perturbation that gives rise to a sterol profile similar to that found in SLOS will likely have significant negative neurodevelopmental consequences, similar to the syndrome. The AY9944 rat model for SLOS is an exhibit in support of this notion and suggests that an effort is warranted to identify small molecules that increase 7DHC levels and alter sterol homeostasis. Human exposure to environmental agents or 
pharmaceutics that increase 7-DHC and reduce cholesterol levels will likely have serious health consequences, particularly during pregnancy. Indeed, a recent clinical study finding that elevated plasma 7-DHC is associated with prescribed aripiprazole and trazodone "provides some information that may be relevant to human risk for teratogenic effects of these drugs", according to the authors of that investigation. ${ }^{23}$

The structures of AY9944, aripiprazole, and trazodone are presented in Figure 6. The three compounds do have similar features, including a central diamine substructure and terminal chloroaromatic units, and they each cause a significant increase in 7-DHC in Neuro2a cell cultures at $10 \mathrm{nM}$ and above. ${ }^{25} \mathrm{~A}$ more substantive understanding of the structural elements that are essential for activity in this screen is the topic of ongoing studies in our laboratory and will be reported in due course.

\section{Screening Methods for 7-DHC}

Powerful methods have been developed for the analysis of sterols, including the biosynthetic precursors to cholesterol shown in Figure $1 .^{30-32}$ We have recently developed a protocol for 7-DHC analysis that involves derivatization of the conjugated diene in a Diels-Alder reaction with the dienophile PTAD. ${ }^{25}$ The procedure when applied to a library screening involves the exposure of an appropriate cell to the library of small molecules, cell lysis in methanol with added isotopically labeled standards, followed by reaction of 7-DHC and its isotopic counterpart with PTAD at room temperature for $30 \mathrm{~min}$. The PTAD-7-DHC adduct can be readily detected by selected reaction monitoring (SRM) in a triple quadrupole mass spectrometer after reverse phase chromatography with an isocratic methanol solvent. Background levels of 7-DHC can be readily detected in 2000 Neuro2a cells, and an added benefit of the method is the detection of "ene" type PTAD products of desmosterol, lanosterol, and any sterol in the Bloch biosynthesis pathway that has a $\Delta 24$ double bond if the appropriate isotopic standards are available. ${ }^{26}$ Indeed, efforts are ongoing to synthesize the isotopic standards for $\Delta 24$ dehydrosterols like zymosterol and dehydrodesmosterol, but these compounds were not available at the time of this study. While the PTAD method does not permit a truly "high throughput" screen, it currently makes possible an assay of lanosterol, desmosterol, 7-DHC, and cholesterol in cells exposed to a small library such as the NIH Clinical Collection. ${ }^{25}$

We note that our initial 384-well screen failed to identify three compounds as "actives" that were found in a subsequent screen that was limited to the 33 antipsychotic medications in the library. While two of the new hits had only modest activity, the third compound (nefazodone) was among the most potent compounds found in the library. The initial screen also gave a false-positive identification to one of the 34 hits (Captopril) found in the library. A greater understanding of structure-activity may help direct future screening strategies by using chemical structure as a predictor of likely hits or raise questions about false discovery for compounds in a library. At any rate, structural considerations, replicate analyses, and extensive validation are suggested when using this relatively new methodology. If a number of hits are identified in a compound class in a broad screen, for example, an abundance of caution suggests that a follow-up based upon structure or compound class would be a prudent investment of additional effort. 


\section{Pharmaceutical Agents That Affect 7-DHC in Neuro2a}

It is of note that prominent among the list of active compounds are several prescribed antipsychotic, antidepressant, and anxiolytic medications. Perospirone, nefazodone, haloperidol, aripiprazole, and trazodone are particularly potent in control Neuro2a cells with melperone, fluoxetine, and risperidone showing less but still significant potency. The effect of active compounds on 7-DHC levels in Neuro2a cells is proportionately greater than the effect observed in the Dhcr7-deficient cell line; see Table 1. Aripiprazole as low as $50 \mathrm{nM}$, for example, can cause an increase in 7-DHC in control Neuro2a from $0.2 \mathrm{ng} / \mu \mathrm{g}$ protein at background to $\sim 25 \mathrm{ng} / \mu \mathrm{g}$ protein, at nearly the same levels that are found in Dhcr7-deficient cells. ${ }^{26}$ 7-DHC levels are, of course, significantly higher in the Dhcr7-deficient cells than in control Neuro2a, and the added effect of a drug on deficient cells is only modest, presumably since they already have a compromised biosynthetic pathway at the 7-DHC $\rightarrow$ cholesterol step. This leveling effect in activity in Dhcr7-deficient cells compared to control cells is observed for all of the compounds shown in Table 1, although all of the compounds but one (CGS 12066B) that increase 7-DHC levels in control Neuro2a cells still increase levels of this sterol in the Dhcr7-deficient cells, albeit by an attenuated amount.

We have previously reported that several antipsychotic medications act on DHCR24 (trifluoperazine, perphenazine, doxepin, and procholorperazine) and the $\Delta 8-7$ isomerase (fluphenazine, perphenazine, and hydroxyzine) in $D h c r 7$-deficient Neuro2a cells, ${ }^{25}$ and other laboratories have reported that haloperidol, clozapine, risperidone, and ziprasidone alter cholesterol metabolism ${ }^{32}$ in HepG2 and HL-60 cells. At the higher concentrations used in these studies (between 5 and $25 \mu \mathrm{M}$ ),${ }^{32}$ multiple enzymes of the biosynthesis pathway are affected by these medications. We also found activity for haloperidol and risperidone at 1 $\mu \mathrm{M}$ in Neuro2a cells and significant effects on cholesterol biosynthesis for haloperidol at concentrations as low as $10 \mathrm{nM} \cdot{ }^{25}$ In Neuro2a cells at $10 \mu \mathrm{M}$ and above, we find that cytotoxicity becomes a major issue for many of these agents.

\section{Desmosterol and Lanosterol in Neuro2a}

The screening method provides information about the effect of compounds in the NIH Clinical Collection on desmosterol and lanosterol in Neuro2a. Desmosterol levels in Neuro2a are relatively high, compared to that of other sterol precursors to cholesterol, and increases in desmosterol are smaller than those found for lanosterol and 7-DHC; see Figure 4. We note, however, that imatinib and progesterone are found to have the highest Z-scores in this study, and they also act as inhibitors of DHCR24 in Dhcr7-deficient Neuro2a cells and are reported to have this activity in other cell lines. ${ }^{33}$ It is also noteworthy that of those compounds that are found in our screen to increase levels of lanosterol in Neuro2a cells, most have a common "azole" substructure that is characteristic of fungicides. The azole substructure acts on the $\mathrm{P} 450$ demethylase that removes the C-14 methyl group of lanosterol, and compounds that affect this enzyme cause a buildup of the precursor substrate, lanosterol. ${ }^{34}$ Indeed, seven of the eight "most actives" in the lanosterol panel in Figure 4C belong to this group of pharmaceuticals that inhibit the C14-demethylase. 


\section{Consequences of Exposures That Lead to Elevated 7-DHC}

The biochemical link between the devastating genetic disorder SLOS and the pharmacological model for that condition based on the small molecule AY9944 raises the possibility that human exposure to compounds that increase 7-DHC levels such as AY9944 (see Figure 4 and Table 1) will exert similar pathophysiological consequences. Indeed, it seems appropriate to raise a number of issues based on the data at hand. Among the questions of potential interest are the following: Are there common pathologies associated with the "active" compounds identified in our screen? Is there evidence that pathologies associated with SLOS find analogy in exposures to small molecules like the "actives" identified in our screen? Is there, in effect, an aripiprazole, trazodone (or other prescribed pharmaceutical) rodent model for SLOS, similar to that of AY9944? Do environmental agents outside of the Pharmacopeia that show "activity" in our screen pose a threat? Are the $1-3 \%$ of the population who are carriers of a SLOS mutation more vulnerable to exposure to "active" small molecules that affect the conversion 7-DHC $\rightarrow$ cholesterol than a control individual?

While studies to directly answer the questions presented above have not been carried out, there is some circumstantial evidence that can be cited. Nefazodone, trazodone, and buspirone, three of the most potent compounds found in our screen, are known to cause mitochondrial dysfunction and loss of cellular viability. ${ }^{35}$ The severity of the exposureassociated toxicities mirrors the compound potency found in our screen with the activity decreasing from nefazodone to trazodone and buspirone. Nefazodone and trazodone were found to reduce mitochondrial membrane potential and cause a decrease in cellular glutathione levels, one conclusion being that these compounds impose an oxidative stress on the exposed cells. In point of fact, 7-DHC is highly prone to free radical chain oxidation reactions, ${ }^{36-38}$ and the pathology of SLOS has been linked to oxidative stress that results from this susceptibility. ${ }^{24,39-44} 7$-DHC is the most reactive lipid toward free radical chain oxidation studied to date, and this inherent reactivity for peroxidation fits with the notion that oxidative stress, free radical peroxidation, and systemic redox status are altered when elevated levels of this sterol are found in biology. Any human exposure that leads to elevated levels of 7-DHC in tissues, for example, the drugs identified in our screen, will likely be linked to a change in lipid redox status as a result of that exposure. Indeed, the vulnerability of 7-DHC to peroxidation and the biological activity of its derived oxysterols were principal reasons that we set out to develop methods to screen for 7-DHC in relevant cell systems.

Any perturbation of sterol homeostasis that results in an elevated cellular level of 7-DHC, such as exposure to nefazodone or other active compounds, will likely be associated with increased lipid peroxidation and oxidative stress.

Another example of a common pathological response to "active" compounds found in our screen is the loss of retinal function that has been associated with the AY9944-exposed rat as well as in instances of vision loss linked to both aripiprazole ${ }^{45}$ and nefazodone ${ }^{46}$ usage. The AY9944 rats undergo selective photoreceptor degeneration, and their responsiveness to light stimulation is markedly reduced. Electrophysiological analysis of the rats showed that the timing of both rod and cone responses to photic stimulation was significantly delayed. It is of some interest then, that a loss of rod retinal function has been reported for SLOS patients 
in recent studies. ${ }^{47,48}$ For all cases cited above, including retinopathies associated with aripiprazole and nefazodone, the primary locus of neural damage is retinal and is likely to have resulted from an induced neurotoxicity.

Finally, we mention that prenatal exposure to certain medications has been associated with an increased risk of autism spectrum disorder (ASD), a condition that is also common to SLOS patients. ${ }^{20,21,49}$ Although the association between the use of antidepressants, antipsychotics, and anxiolytic medications and ASD is still controversial, recent studies have concluded that second and/or third trimester use of drugs in these categories are statistically associated with an increased risk of ASD. ${ }^{50,51}$ While the ASD phenotype is broad and the causes of the disorder remain unknown, the parallel between SLOS, a single gene mutation that causes a disruption of sterol homeostasis, and small molecules that also perturb the cholesterol biosynthetic pathway and their corresponding associations with ASD seems worthy of additional investigation. In this regard, an interplay between genetics and environment risk factors during the prenatal period may well play a role in some neurodevelopmental disorders, ${ }^{52-54}$ and it seems reasonable to suggest that the $1 \%$ of the population who are carriers of a SLOS mutation may be particularly vulnerable to exposure to compounds that affect the conversion of 7-DHC $\rightarrow$ cholesterol.

\section{Supplementary Material}

Refer to Web version on PubMed Central for supplementary material.

\section{Acknowledgments}

Assay development and preparation were carried out with assistance from Paige Vinson and Joshua Bauer in the Vanderbilt High-throughput Screening Core Facility, which receives institutional support through the Vanderbilt Institute of Chemical Biology. The NIH Clinical Collection is provided through the National Institutes of Health Molecular Libraries Roadmap Initiative. We thank Bruce Pfeffer of the University of Buffalo for his very helpful comments about the retinopathy associated with AY9944 rats. We acknowledge helpful comments from Professor Libin $\mathrm{Xu}$ of the University of Washington as well as those from a thoughtful reviewer of this manuscript.

Funding

Funding was provided by The National Institutes of Health (NICHD R01 HD064727 to N.A.P., NIEHS R01 ES024133 to N.A.P. and Z.K., and R21 ES024666 to N.A.P.).

\section{ABBREVIATIONS}

7-DHC

Des

Lan

Chol

PTAD

SLOS

DHCR7 7-dehydrocholesterol

desmosterol

lanosterol

cholesterol

4-phenyl-1,2,4-triazoline-3,5-dione

Smith-Lemli-Opitz syndrome

7-dehydrocholesterol reductase

mass spectrometry

MS 


$\begin{array}{ll}\text { APCI } & \text { atmospheric pressure chemical ionization } \\ \text { SRM } & \text { selected reaction monitoring } \\ \text { UPLC-MS } & \text { ultrahigh pressure liquid chromatography-mass spectrometry } \\ \text { HPLC-UV } & \text { high pressure liquid chromatography-ultraviolet spectroscopy } \\ \text { MeOH } & \text { methanol } \\ \text { NMR } & \text { nuclear magnetic resonance } \\ \text { TIC } & \text { total ion current } \\ \text { FBS } & \text { fetal bovine serum } \\ \text { DMEM } & \text { Dulbecco's modified Eagle's medium } \\ \text { PBS } & \text { phosphate buffered saline } \\ \text { DMSO } & \text { dimethyl sulfoxide } \\ \text { HTS } & \text { high throughput screening }\end{array}$

\section{References}

1. Nes WD. Biosynthesis of cholesterol and other sterols. Chem Rev. 2011; 111:6423-6451. [PubMed: 21902244]

2. Li, JJ. Triumph of the Heart, The Story of Statins. Oxford University Press; London: 2009.

3. Kolf-Clauw M, Chevy F, Wolf C, Siliart B, Citadelle D, Roux C. Inhibition of 7-dehydrocholesterol reductase by the teratogen AY9944: a rat model for Smith-Lemli-Opitz syndrome. Teratology. 1996; 54:115-125. [PubMed: 8987154]

4. Gaoua W, Chevy F, Roux C, Wolf C. Oxidized derivatives of 7-dehydrocholesterol induce growth retardation in cultured rat embryos: a model for antenatal growth retardation in the Smith-LemliOpitz syndrome. J Lipid Res. 1999; 40:456-463. [PubMed: 10064734]

5. Gaoua W, Wolf C, Chevy F, Ilien F, Roux C. Cholesterol deficit but not accumulation of aberrant sterols is the major cause of the teratogenic activity in the Smith-Lemli-Opitz syndrome animal model. J Lipid Res. 2000; 41:637-646. [PubMed: 10744785]

6. Fliesler SJ. Retinal degeneration in a rat model of smith-lemli-opitz syndrome: thinking beyond cholesterol deficiency. Adv Exp Med Biol. 2010; 664:481-489. [PubMed: 20238050]

7. Fliesler SJ, Peachey NS, Richards MJ, Nagel BA, Vaughan DK. Retinal degeneration in a rodent model of Smith-Lemli-Opitz syndrome: electrophysiologic, biochemical, and morphologic features. Arch Ophthalmol. 2004; 122:1190-1200. [PubMed: 15302661]

8. Xu G, Salen G, Shefer S, Ness GC, Chen TS, Zhao Z, Tint GS. Reproducing abnormal cholesterol biosynthesis as seen in the Smith-Lemli-Opitz syndrome by inhibiting the conversion of 7dehydrocholesterol to cholesterol in rats. J Clin Invest. 1995; 95:76-81. [PubMed: 7814648]

9. Tu C, Li J, Jiang X, Sheflin LG, Pfeffer BA, Behringer M, Fliesler SJ, Qu J. Ion-current-based proteomic profiling of the retina in a rat model of Smith-Lemli-Opitz syndrome. Mol Cell Proteomics. 2013; 12:3583-3598. [PubMed: 23979708]

10. Kelley RI. Inborn errors of cholesterol biosynthesis. Adv Pediatr. 2000; 47:1-53. [PubMed: 10959439]

11. Kelley RI, Hennekam RC. The Smith-Lemli-Opitz syndrome. J Med Gen. 2000; 37:321-335.

12. Linck LM, Hayflick SJ, Lin DS, Battaile KP, Ginat S, Burlingame T, Gibson KM, Honda M, Honda A, Salen G, Tint GS, Connor WE, Steiner RD. Fetal demise with Smith- Lemli-Opitz syndrome confirmed by tissue sterol analysis and the absence of measurable 7-dehydrocholesterol $\Delta 7$-reductase activity in chorionic villi. Prenatal Diagn. 2000; 20:238-240. 
13. Witsch-Baumgartner M, Fitzky BU, Ogorelkova M, Kraft HG, Moebius FF, Glossmann H, Seedorf U, Gillessen-Kaesbach G, Hoffmann GF, Clayton P, Kelley RI, Utermann G. Mutational spectrum in the Delta7-sterol reductase gene and genotype-phenotype correlation in 84 patients with SmithLemli-Opitz syndrome. Am J Hum Genet. 2000; 66:402-412. [PubMed: 10677299]

14. Wassif CA, Zhu P, Kratz L, Krakowiak PA, Battaile KP, Weight FF, Grinberg A, Steiner RD, Nwokoro NA, Kelley RI, Stewart RR, Porter F. Biochemical, phenotypic and neurophysiological characterization of a genetic mouse model of RSH/Smith-Lemli-Opitz syndrome. Hum Mol Genet. 2001; 10:555-564. [PubMed: 11230174]

15. Javitt NB. Oxysterols: functional significance in fetal development and the maintenance of normal retinal function. Curr Opin Lipidol. 2007; 18:283-288. [PubMed: 17495602]

16. Porter F. Smith-Lemli-Opitz syndrome: pathogenesis, diagnosis and management. Eur J Hum Genet. 2008; 16:535-541. [PubMed: 18285838]

17. Cross JL, Iben J, Simpson CL, Thurm A, Swedo S, Tierney E, Bailey-Wilson JE, Biesecker LG, Porter FD, Wassif CA. Determination of the allelic frequency in Smith-Lemli-Opitz syndrome by analysis of massively parallel sequencing data sets. Clin Genet. 2015; 87:570-575. [PubMed: 24813812]

18. Witsch-Baumgartner M, Schwentner I, Gruber M, Benlian P, Bertranpetit J, Bieth E, Chevy F, Clusellas N, Estivill X, Gasparini G, Giros M, Kelley RI, Krajewska-Walasek M, Menzel J, Miettinen T, Ogorelkova M, Rossi M, Scala I, Schinzel A, Schmidt K, Schonitzer D, Seemanova E, Sperling K, Syrrou M, Talmud PJ, Wollnik B, Krawczak M, Labuda D, Utermann G. Age and origin of major Smith-Lemli-Opitz syndrome (SLOS) mutations in European populations. J Med Gen. 2008; 45:200-209.

19. Waterham HR, Hennekam RCM. Mutational spectrum of Smith-Lemli-Opitz syndrome. Am J Med Genet, Part C 160C. 2012:263-284.

20. Bukelis I, Porter F, Zimmerman AW, Tierney E. Smith-Lemli-Opitz syndrome and autism spectrum disorder. Am J Psychiatry. 2007; 164:1655-1661. [PubMed: 17974928]

21. Lee RWY, Tierney E. Hypothesis: The Role of Sterols in Autism Spectrum Disorder. Aut Res Treat. 2011; 2011:1-7.

22. Battaile KP, Battaile BC, Merkens LS, Maslen CL, Steiner RD. Carrier frequency of the common mutation IVS8-1G > C in DHCR7 and estimate of the expected incidence of Smith-Lemli-Opitz syndrome. Mol Genet Metab. 2001; 72:67-71. [PubMed: 11161831]

23. Hall P, et al. Aripiprazole and trazodone cause elevations of 7-dehydrocholesterol in the absence of Smith-Lemli-Opitz Syndrome. Mol Genet Metab. 2013; 110:176-178. [PubMed: 23628460]

24. Xu L, Korade Z, Rosado DA, Liu W, Lamberson CR, Porter NA. An oxysterol biomarker for 7dehydrocholesterol oxidation in cell/mouse models for Smith-Lemli-Opitz syndrome. J Lipid Res. 2011; 52:1222-1233. [PubMed: 21402677]

25. Korade Z, Kim HY, Tallman KA, Liu W, Koczok K, Balogh I, Xu L, Mirnics K, Porter NA. The Effect of Small Molecules on Sterol Homeostasis: Measuring 7-Dehydrocholesterol in Dhcr7deficient Neuro2a Cells and Human Fibroblasts. J Med Chem. 2016; 59:1102-1115. [PubMed: 26789657]

26. Liu W, Xu L, Lamberson C, Haas D, Korade Z, Porter NA. A highly sensitive method for analysis of 7-dehydrocholesterol for the study of Smith-Lemli-Opitz syndrome. J Lipid Res. 2014; 55:329337. [PubMed: 24259532]

27. Zhang JH, Chung TDY, Oldenburg KR. A Simple Statistical Parameter for Use in Evaluation and Validation of High Throughput Screening Assays. J Biomol Screening. 1999; 4:67-73.

28. Larsen, RJ.; Morris, ML. An Introduction to Mathematical Statistics and Its Applications. 3rd. Pearson; London, U.K: 2000. p. 282

29. Xu L, Liu W, Sheflin LG, Fliesler SJ, Porter NA. Novel oxysterols observed in tissues and fluids of AY9944-treated rats - a model for Smith-Lemli-Opitz Syndrome. J Lipid Res. 2011; 52:18101820. [PubMed: 21817059]

30. McDonald JG, Thompson BM, McCrum EC, Russell DW. Extraction and analysis of sterols in biological matrices by high performance liquid chromatography electrospray ionization mass spectrometry. Methods Enzymol. 2007; 432:145-170. [PubMed: 17954216] 
31. Stiles AR, Kozlitina J, Thompson BM, McDonald JG, King KS, Russell DW. Genetic, anatomic, and clinical determinants of human serum sterol and vitamin D levels. Proc Natl Acad Sci U S A. 2014; 111:E4006-E4014. [PubMed: 25201972]

32. Canfran-Duque A, Casado ME, Pastor O, Sanchez-Wandelmer J, de la Pena G, Lerma M, Mariscal P, Bracher F, Lasuncion MA, Busto R. Atypical antipsychotics alter cholesterol and fatty acid metabolism in vitro. J Lipid Res. 2013; 54:310-324. [PubMed: 23175778]

34. Jansen M, Wang W, Greco D, Bellenchi GC, di Porzio U, Brown AJ, Ikonen E. What dictates the accumulation of desmosterol in the developing brain? FASEB J. 2013; 27:865-870. [PubMed: 23230282]

34. Zarn JA, Bruschweiler BJ, Schlatter JR. Azole fungicides affect mammalian steroidogenesis by inhibiting sterol 14 alpha-demethylase and aromatase. Environ Health Perspect. 2003; 111:255261. [PubMed: 12611652]

35. Dykens JA, Jamieson JD, Marroquin LD, Nadanaciva S, Xu JJ, Dunn MC, Smith AR, Will Y. In vitro assessment of mitochondrial dysfunction and cytotoxicity of nefazodone, trazodone, and buspirone. Toxicol Sci. 2008; 103:335-345. [PubMed: 18344530]

36. Porter NA. A Perspective on Free Radical Autoxidation: The Physical Organic Chemistry of Polyunsaturated Fatty Acid and Sterol Peroxidation. J Org Chem. 2013; 78:3511-3524. [PubMed: 23445181]

37. Xu L, Davis TA, Porter NA. Rate constants for peroxidation of polyunsaturated fatty acids and sterols in solution and in liposomes. J Am Chem Soc. 2009; 131:13037-13044. [PubMed: 19705847]

38. Yin H, Xu L, Porter NA. Free Radical Lipid Peroxidation: Mechanisms and Analysis. Chem Rev. 2011; 111:5944-5972. [PubMed: 21861450]

39. Korade Z, Xu L, Harrison FE, Ahsen R, Hart SE, Folkes OM, Mirnics K, Porter NA. Antioxidant Supplementation Ameliorates Molecular Deficits in Smith-Lemli-Opitz Syndrome. Biol Psychiatry. 2014; 75:215-222. [PubMed: 23896203]

40. Korade Z, Xu L, Mirnics K, Porter NA. Lipid biomarkers of oxidative stress in a genetic mouse model of Smith-Lemli-Opitz syndrome. J Inherited Metab Dis. 2013; 36:113-122. [PubMed: 22718275]

41. Korade Z, Xu L, Shelton R, Porter NA. Biological activities of 7-dehydrocholesterol-derived oxysterols: implications for Smith-Lemli-Opitz syndrome. J Lipid Res. 2010; 51:3259-3269. [PubMed: 20702862]

42. Xu L, Korade Z, Porter NA. Oxysterols from free radical chain oxidation of 7-dehydrocholesterol: product and mechanistic studies. J Am Chem Soc. 2010; 132:2222-2232. [PubMed: 20121089]

43. Xu L, Korade Z, Rosado DA, Mirnics K, Porter N. A. Metabolism of oxysterols derived from nonenzymatic oxidation of 7-dehydro cholesterol in cells. J Lipid Res. 2013; 54:1135-1143. [PubMed: 23381570]

44. Xu L, Mirnics K, Bowman AB, Liu W, Da J, Porter NA, Korade Z. DHCEO accumulation is a critical mediator of pathophysiology in a Smith-Lemli-Opitz syndrome model. Neurobiol Dis. 2012; 45:923-929. [PubMed: 22182693]

45. Faure C, Audo I, Zeitz C, Lefessier J, Robert M. Aripiprazole-induced chorioretinopathy: multimodal imaging and electrophysiological features. Doc Ophthalmol. 2015; 131:35-41. [PubMed: 25791769]

46. Luu C, Kiely P, Crewther D, Kowal L, Crewther S. Central and peripheral vision loss associated with nefazodone usage. Doc Ophthalmol. 2003; 106:319-325. [PubMed: 12737510]

47. Elias ER, Hansen RM, Irons M, Quinn NB, Fulton AB. Rod photoreceptor responses in children with Smith-Lemli-Opitz syndrome. Arch Ophthalmol. 2003; 121:1738-1743. [PubMed: 14662594]

48. Garry D, Hansen RM, Moskowitz A, Elias ER, Irons M, Fulton AB. Cone ERG responses in patients with Smith-Lemli-Opitz Syndrome (SLOS). Doc Ophthalmol. 2010; 121:85-91. [PubMed: 20440536]

49. Sikora DM, Merkens LS, Steiner RD. The near universal presence of autism spectrum disorders in children with Smith-Lemli-Opitz syndrome. Am J Med Genet, Part A 140A. 2006:1511-1518. 
50. Källén B, Borg N, Reis M. The Use of Central Nervous System Active Drugs During Pregnancy. Pharmaceuticals. 2013; 6:1221-1286. [PubMed: 24275849]

51. Boukhris T, Sheehy O, Mottron L, Bérard A. Antidepressant Use During Pregnancy and the Risk of Autism Spectrum Disorder in Children. JAMA Pediatrics. 2016; 170:117-124. [PubMed: 26660917]

52. Risch N, Hoffmann TJ, Anderson M, Croen LA, Grether JK, Windham GC. Familial recurrence of autism spectrum disorder: evaluating genetic and environmental contributions. Am J Psychiatry. 2014; 171:1206-1213. [PubMed: 24969362]

53. Lyall K, Schmidt RJ, Hertz-Picciotto I. Maternal lifestyle and environmental risk factors for autism spectrum disorders. Int J Epidem. 2014; 43:443-464.

54. Grandjean P, Landrigan PJ. Neurobehavioural effects of developmental toxicity. Lancet Neurol. 2014; 13:330-338. [PubMed: 24556010] 


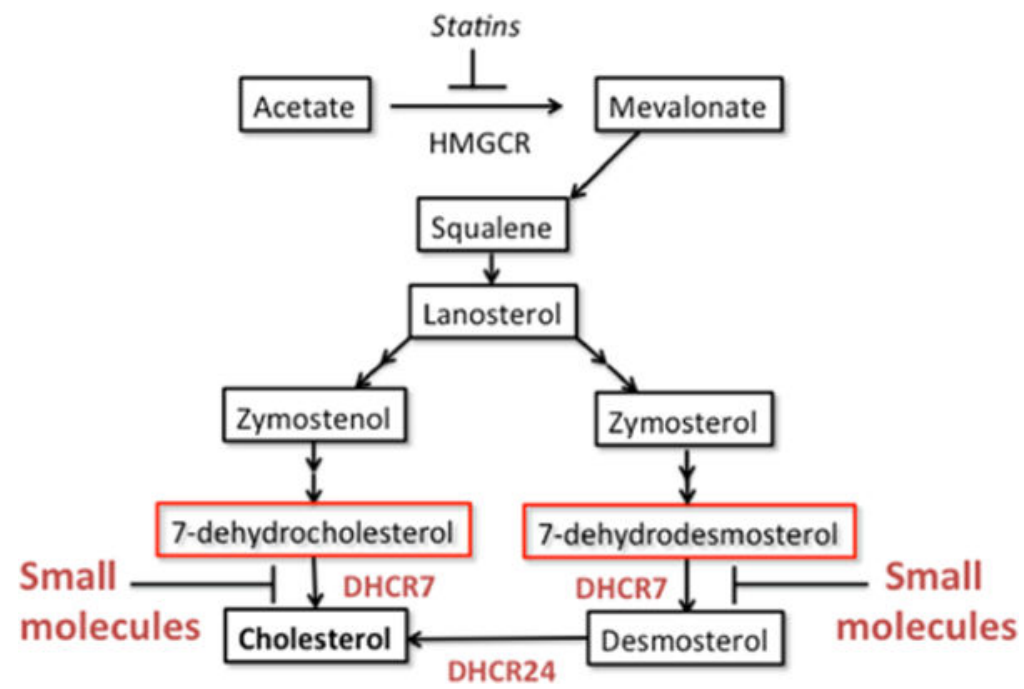

Figure 1.

Small molecules inhibit late-stage transformations in cholesterol biosynthesis. 


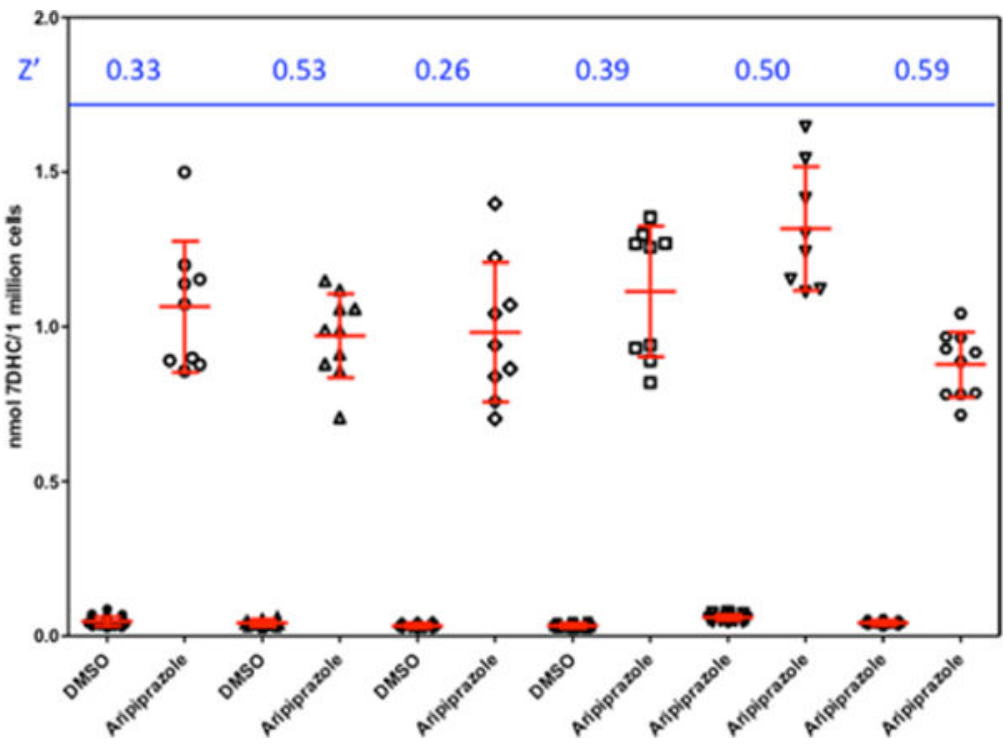

Figure 2.

Nanomoles of 7-DHC in control (DMSO) and aripiprazole (100 nM) wells on six 384-well plates. 


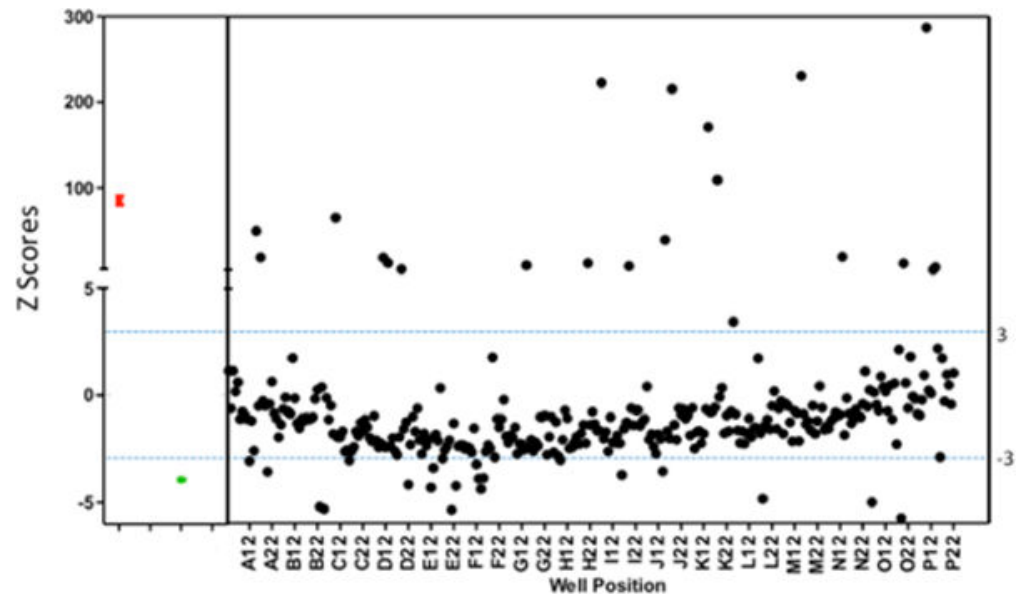

Figure 3.

Z-Score for 7-DHC in Neuro2a cells treated for $24 \mathrm{~h}$ with compounds in the NIH Clinical Collection. Positive controls, $100 \mathrm{nM}$ of aripiprazole in red, and pitavastatin in green are shown at the left and +3 and $-3 \mathrm{Z}$-score cutoffs in blue. The Z-score of zero is set by the analysis of 20 control DMSO wells. 

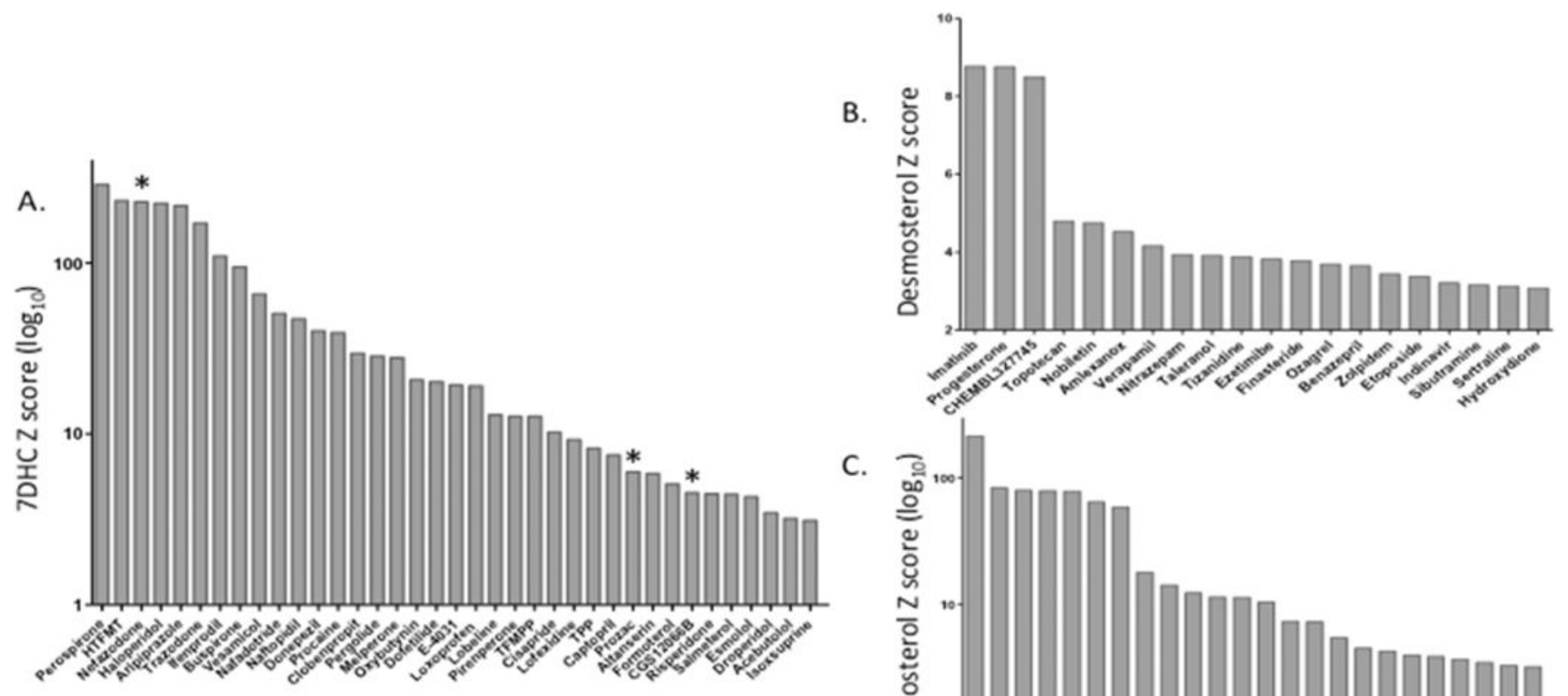

C.

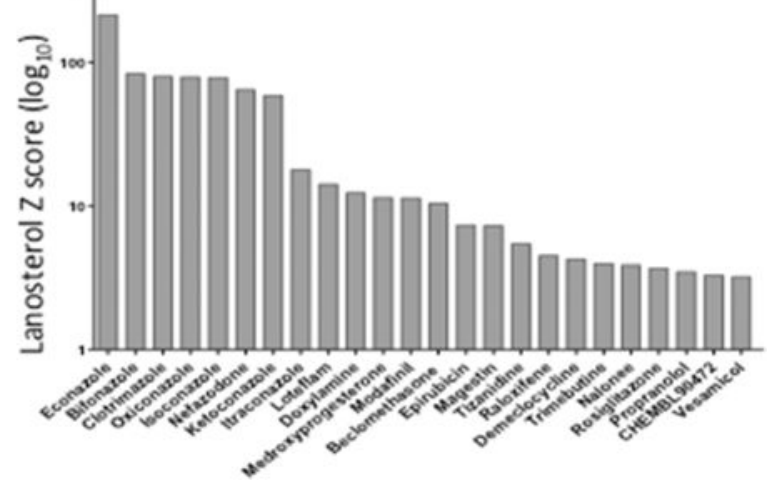

Figure 4.

Compounds in the NIH Clinical Collection that give a Z-Score of greater than +3 at $1 \mu \mathrm{M}$ when Neuro2a cells are treated with the compound for $24 \mathrm{~h}$. (A) For 7-DHC, the Z-score is shown as a $\log$ plot. * indicates compounds found on a triplicate rescreen. Captopril did not validate in a subsequent rescreen. HTFMT = histamine trifluoromethyl toluidide; TFMPP = $N$-(3-trifluoromethylphenyl)piperazine. TPP: 1-[3-(2,4,6-

trimethoxybenzoyl)propyl]pyrrolidinium chloride. (B) For desmosterol. (C) For lanosterol, the $\mathrm{Z}$-score is shown as a log plot. Z-scores shown are averages of assays on duplicate plates. 
(A) Perospirone

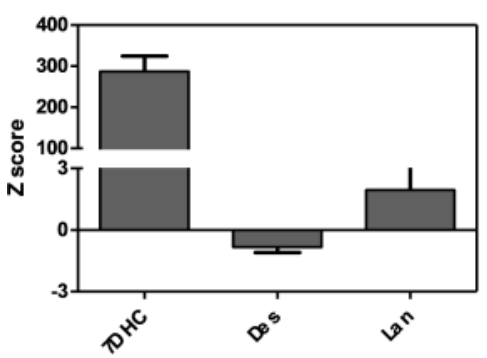

(D) Trazodone

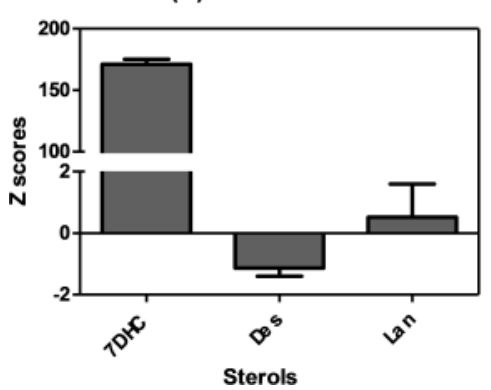

(B) Aripiprazole

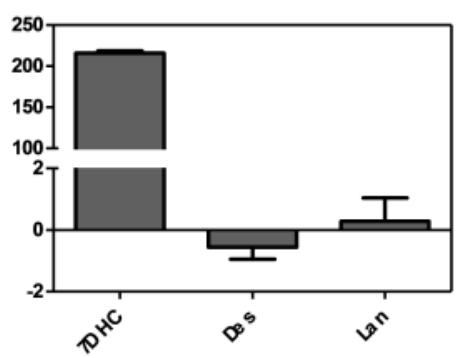

(E) Ifenprodil

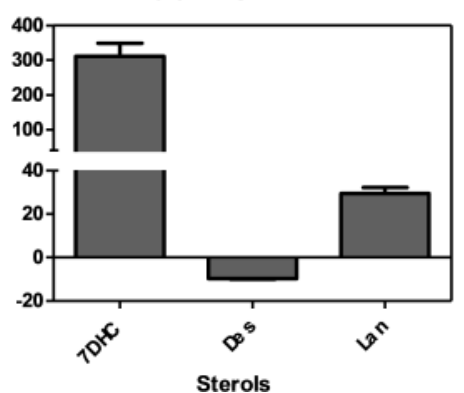

(C) Nefazodone

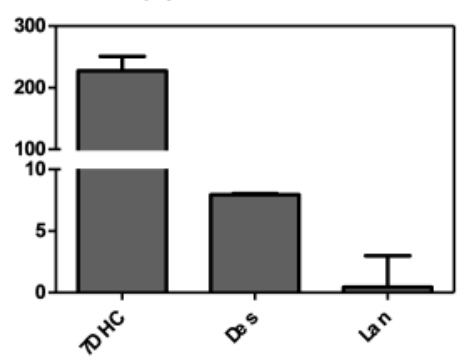

(F) Risperidone

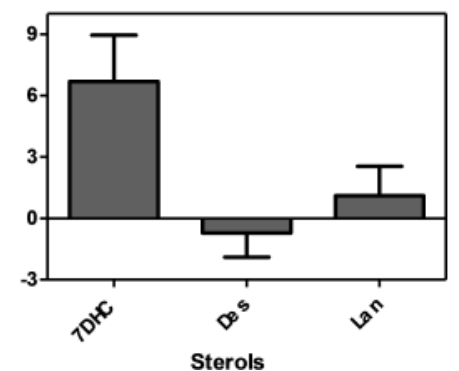

Figure 5.

Typical 7-DHC, desmosterol (Des), and lanosterol (Lan) profiles for compounds in the NIH Clinical Collection that give a Z-score of greater than +3 at $1 \mu \mathrm{M}$ when Neuro2a cells are treated with the compound for 24 h. (A) Perospirone; (B) aripiprazole; (C) nefazodone; (D) trazodone; (E) ifenprodil; (F) rispiridone. Sterol profiles for A-D are typical for screening hits. The exceptions are nefazodone, dofetilide, and flluoxetine that give profiles like nefazodone. 


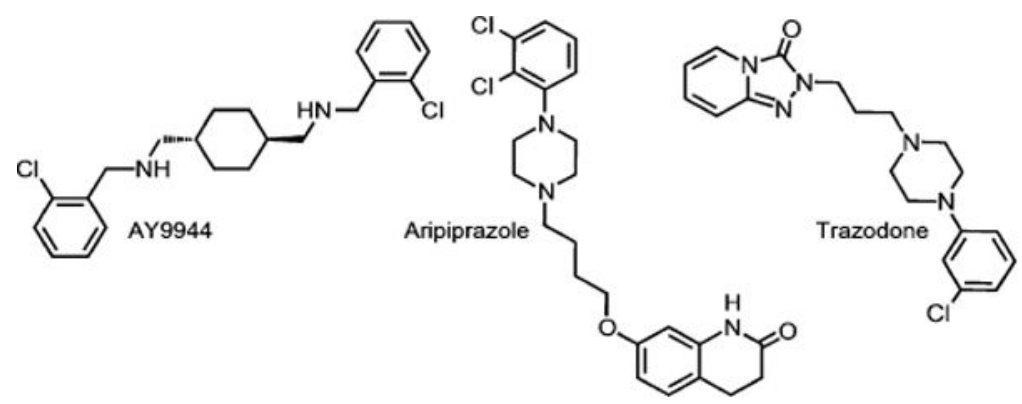

Figure 6.

Structures of AY9944, aripiprazole, and trazodone, each of which causes significant increases in 7-DHC in Neuro2a cells. 


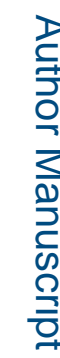

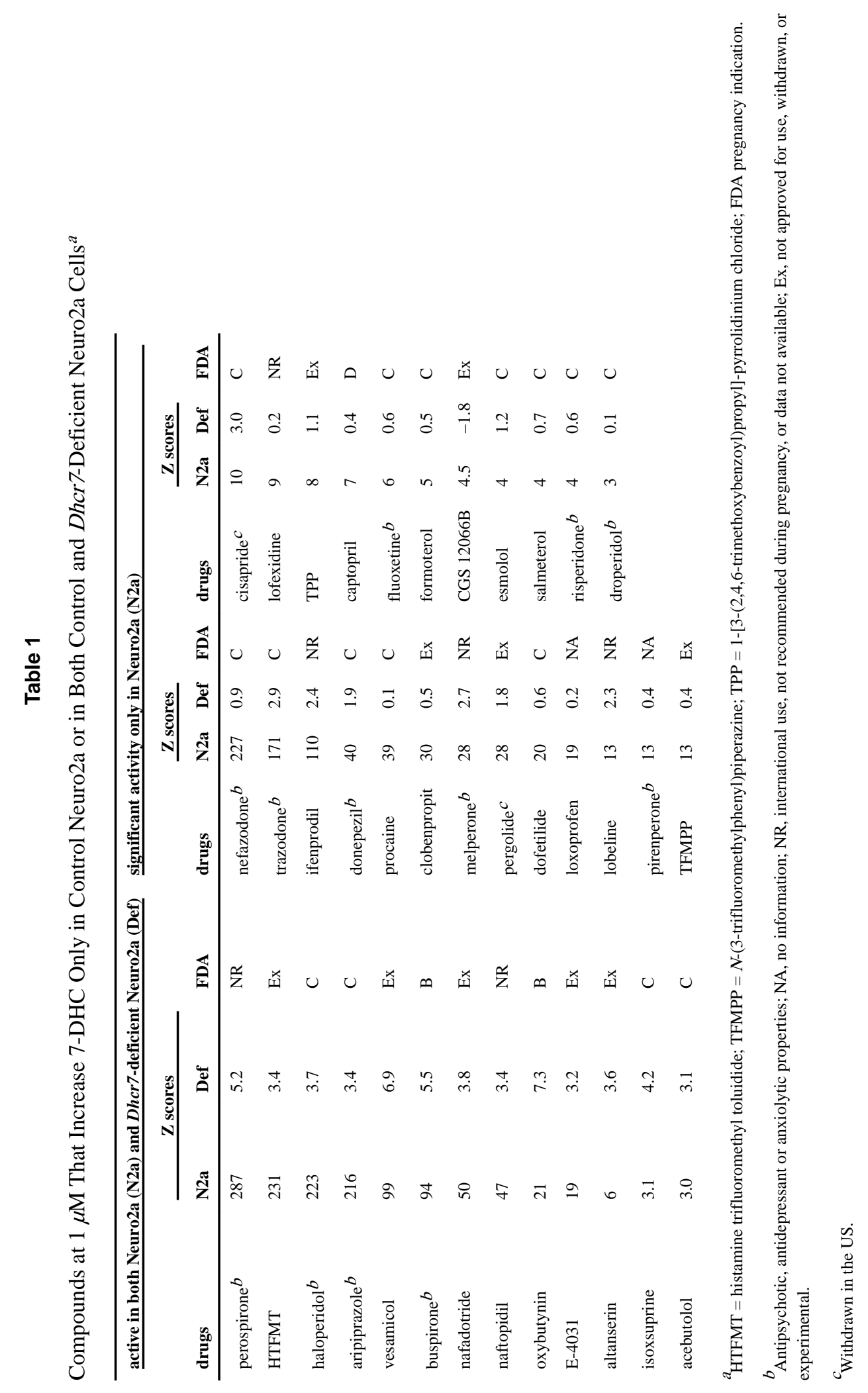

Chem Res Toxicol. Author manuscript; available in PMC 2017 May 16. 